\title{
MODE - REGRESSION BASED MODEL FOR SHORT TERM LOAD FORECASTING
}

\author{
Ahmad Al-Subhi ${ }^{1}$, and Chokri Belhadj Ahmad ${ }^{2}$ \\ 1 Electrical Power Engineering Technology Department, Yanbu Industrial College, Saudi Arabia \\ 2 Electrical Engineering Department, King Fahd University of Petroleum \& Minerals, Saudi Arabia \\ Email: alsubhia@yic.edu.sa
}

\begin{abstract}
This paper presents Short Term Load Forecasting (STLF) model using mode-regression based technique for a residential area in Yanbu Industrial City (YIC) in the Kingdom of Saudi Arabia (KSA). Hourly load, temperature and humidity data are collected for three consecutive years from 2009 to 2011. In this technique, all the days with similar characteristics are classified into groups called modes. The daily load behavior is classified based on identified behavioral modes representing religious, social, and official occasions, in addition to environmental conditions. The daily load signal is decomposed into timevarying and non-time varying components. Each component is forecasted individually. The first model uses harmonics regression analysis to forecast the time-varying component which is only the daily load curve with zero mean value. To forecast the nontime varying component, regression analysis using Eureqa software is used to forecast the average load consumption for the next day. In the end, the two models are added algebraically to constitute the next day load forecasting model. The obtained model formulation testing has shown satisfactory forecasting results. A comparative study is conducted to prove the effectiveness of the model proposed.The results obtained in this work are compared with other published work that uses different method applied to the same data.
\end{abstract}

Keywords: Load forecasting, Modes analysis, Harmonics regression.

\section{INTRODUCTION}

The sharp rise in energy consumption, national income, growth rate, and future governmental plans make the load forecasting in the KSA an important topic. The KSA is a developing country that is witnessing rapid urbanization, economic developments, substantial increase in oil revenue and new infrastructure projects. This causes a huge and growing demand for electricity. As a result the generation of electricity, transmission and distribution of electricity in the KSA are very important subjects for the decision makers in the Kingdom, making the studies and research in the field of electricity demand to be very useful.

In YIC, an industrial city on the western coast of the KSA, the load consumption is heavily affected by cooling appliances during the summer season, a season characterized by relatively high temperature and humidity levels. When the temperature increases, the load consumption increases due to the heavy usage of air conditioners and other cooling devices.

In general, the problem of load forecasting in the KSA is very complicated and challenging. Many complex factors affect the load level due to: 
- The rapid growth in the economy, larger diversity in commercial activities, and high rate of population increase of the Kingdom are major factors that affect load level.

- There is a large gap between maximum and minimum temperature values depending on the seasons (temperature hit usually high values in the July-September period), and

- Religious and school holidays are base on the lunar Hijri calendar. These holidays weigh heavily on the load consumption. The most famous religious festivals are Ramadan (the month of fasting for Muslims), Eid Al-fitr (celebration on day that marks the end of Ramadan), and the first two weeks of the twelfth month of Hijri calendar, Dul-Hijjah, when Hajj (the pilgrimage to Makkah) takes place. During the month of Ramadan, load consumption changes due to changing in social and commercial activities. Moreover, religious holidays and schools are cyclic but irregular to some extent. The process forecasting demand becomes more difficult than the process of forecasting common behaviours of people's activities [1].

The objective of this paper is to present the STLF model using mode-regression based technique for a residential area in YIC in KSA. The local water and electricity company, Marafiq, provided data for hourly load, temperature and humidity data are provided for three consecutive years from 2009 to 2011 . The data for 2009 and 2010 will be used for model building while the 2011 data is used to test the model.

Several methods which vary in the complexity of estimation approaches and functional forms have been proposed to improve the accuracy of load forecasting. The STLF methods can be categorized into two main categories: artificial intelligence including Fuzzy Logic Inference [2,3,4], Expert systems [5,6,7], Particle Swarm Optimization (PSO) $[8,9,10]$, and wavelets $[11,12,13]$; and statistical methods including regression methods $[14,15,16]$, similar day approaches $[17,18,19]$, time series $[20,21,22]$ and support vector regression (SVR) [23,24,25].

In this paper, the study is based on residential modes analyses which are groups of days that have similar behavior such as Ramadan days, Eid days, cold days, hot days and holidays. In addition, the impact of the surrounding environmental conditions is studied. The mandate is to formulate these mentioned load modes in a composed model. The model is composed of a time-varying component predicted by harmonics regression and a fixed component predicted by regression analysis using Eureqa software. The paper is structured as follows. In section two, modes analysis and the concept of mode-regression model are discussed. The analysis of the results obtained from the proposed model is presented in section three. After that, a comparison with other published work is performed in section four. Finally, conclusions are shown and recommendations are presented in section five.

\section{MODES ANALYSIS}

\subsection{Modes Identification and Classification}

Daily load data can be divided into distinct behavioral patterns called behavioral modes or, simply, modes. An extensive analysis is needed to identify the existing modes according to the characteristics and behaviors of the area to be studied. For example, a ten-day period load profile of the studied residential area for years 2009 and 2010 with different intervals like Ramadan, Eid Al-Fitr day is shown in Figure 1. 


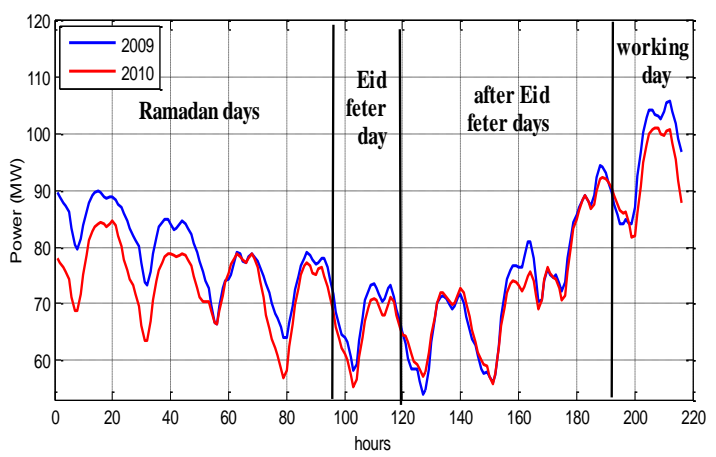

Fig.1. Ramadan days, Eid Al-Fitr day, the days after Eid Al-Fitr and working day for years 2009 and 2010

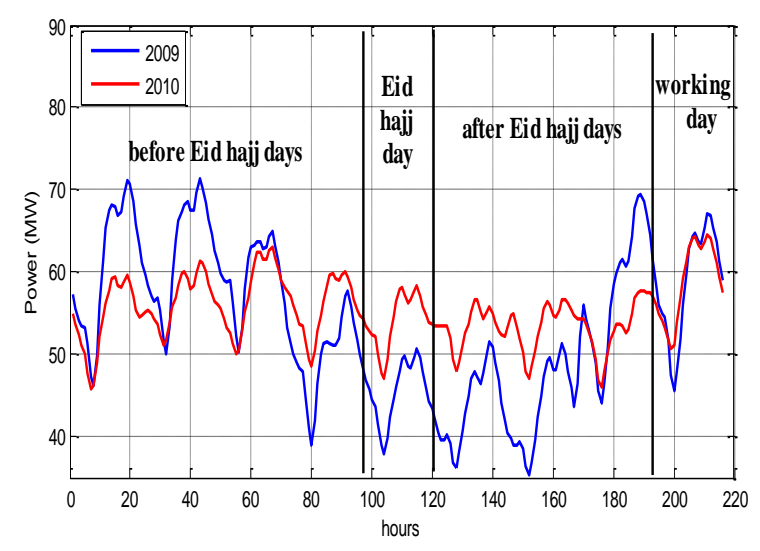

Fig.2. Before Eid hajj days, Eid hajj day,after Eid hajj days and working day for years 2009 and 2010

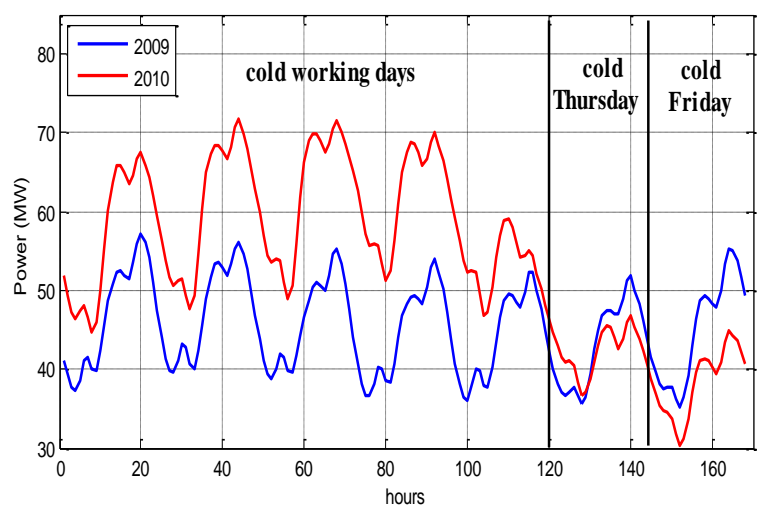

Fig.3. Cold working days, Thursday and Friday from years 2009 and 2010

In addition, another period covering Eid Hajj day, after Eid Hajj days and a working day is shown in Figure 2. It is clear that there is a difference between these days according to people activities and weather conditions. Moreover, a sample week starting from Saturday to Friday during winter period for years 2009 and 2010 can be seen in Figure 3.
When the data was collected, the workdays in the KSA were Saturdays to Wednesdays while the weekend was Thursdays and Fridays. It is obvious that there is a difference between the shape of the load on a typical weekend day, such as Friday and a working day like Saturday or Sunday. The similarity of the days in the same intervals for different years is also noted. The same analysis is done for all other intervals of the year like hot periods, mid-year vacation and summer vacation.

Therefore, it is concluded that there are different characteristics of days or group of days during the year. Also, there is a clear similarity between the days of the same period in different years that support the data to be classified to different modes with special characteristics. As a result, it is revealed that the entire year can be divided to different modes which are Ramadan mode, Eid Al-Fitr mode, the days after Eid Al-Fitr mode, Eid Hajj day mode, after Eid Hajj days mode, cold normal days mode, cold Thursdays mode, cold Fridays mode, hot normal days mode, hot Thursdays mode and hot Fridays mode. Some additional modes may be included like before Eid Hajj days, mid-year vacation days, summer vacation and mid-term vacation. This will increase the accuracy of the results. Every mode has its own behavior which is different from other modes' characteristics.

An interesting period is Ramadan month which is the month of fasting. In this lunar month, people activities are totally different from their activities in any other month. This month is characterized by different dining hours, less work hours. There is almost no difference between week days and weekend days. Also, almost there is no difference between schools days and vacations. This is because the load depends mainly on people's activities and fasting time which are almost similar for all days of this month of fasting. 
So, as seen in Figure 1, Ramadan days have their own characteristics, which are totally different from the characteristics of other days of the year. Because of fasting during the day, there is no lunch period, unlike the other days of the year. Moreover, the evening load is higher in Ramadan days with extended hours. Eid Al-Fitr day is the first day coming directly after the month of fasting and it has also a special behavior. A sharp decrease in load consumption is noted as shown in Figure 1. The residential load on this day is very low due to people's outdoor activities especially in the morning time. The load behavior at lunch time is back to normal.

After Eid al-Fitr days mode is the group of days coming directly after Eid Al-Fitr. The load increases gradually because people are coming gradually back to normal behaviors. This gradual increase in load continues until the starting of the next interval, which are the normal working days as shown in Figure 1.

On Eid Hajj day, a sharp decrease in the load is observed compared to the days preceding it and the days after it. For after-Eid Hajj day mode, the load curve gradually increases in almost the same manner as the after Eid AlFitr days mode and continues until the beginning of workdays period as shown in Figure 2.

Cold workdays mode is the winter period from Saturdays to Wednesdays. Figure 3 shows the low power demand for 2009 and 2010 for a typical week in February starting from Saturday to Friday. For residential areas, the low usage of cooling devices load has greatly reduced the load demand level during all week days. The dip during the lunch time is also clearly noticed due to after lunch snap time. Moreover, there is a fall in the load curve on weekends, compared to the weekdays of this interval. As a result, it can be concluded that the electrical load on weekends (Thursday and Friday) is usually lower than that of workdays (Saturday to Wednesday). This is due to the fact that indoor activities on workdays are usually at higher level than on weekends. On Thursdays, the load is relatively high at lunch time because people are off and usually have lunch at homes. On Fridays, people tend to wake up late; thus, sleeping time is extended. On this day, there is Juma'a prayer, which is a very important outdoor activity. This obligatory weekly gathering has a main impact on load curve behavior making the residential load to drop at this time as shown in Figure 3.

\subsection{TIMe VARYing COMPONENT MODEL FORMULATION}

In this formulation, only the daily load shape is extracted without its average value meaning that the average value of the curve is zero. After calculating the average representative day, its average value (which will be forecasted in the next section) is subtracted from all 24hour values making the entire curve to have a zero mean value. The objective is to model the equations of the modes. Every mode is represented by its average day with zero mean value. Since the days of any mode have similar behavior, its average day will be closest representative. For all modes, the same equation model used is:

$P(t)=\sum_{1}^{m}\left(\mathrm{a}_{\mathrm{n}} \cos \left(\omega_{\mathrm{n}} \mathrm{t}\right)+b_{\mathrm{n}} \sin \left(\omega_{\mathrm{n}} \mathrm{t}\right)\right)$

where the coefficients $a_{n}$ and $b_{n}$ are constants that will be evaluated using least square method. $\omega$ is the frequency which equals $\frac{2 \pi}{T}$, where $\mathrm{T}$ is the period of the day which has a value of 24 hours. $\mathrm{t}$ is the time from 1 to 24 , $\mathrm{n}$ is the harmonic number and $m$ is the total number of harmonics. Of course, including more harmonics in the model improves the solution. At the end, an equation containing load consumption as a function of time will be established. So, after substituting for 
$\omega=\frac{2 \pi}{24}=\frac{\pi}{12}$, the final model of each mode is of the form:

$$
P_{\text {mode__mode }}=\sum_{n=1}^{m}\left(\mathrm{a}_{\mathrm{n}} \cos \left(\mathrm{n} * \frac{\pi}{12} \mathrm{t}\right)+b_{\mathrm{n}} \sin \left(\mathrm{n} * \frac{\pi}{12} \mathrm{t}\right)\right)
$$

Every model represents a mode. All modes have the same form of equation 2 . The difference is only in the values of the constants $a_{n}$ and $b_{n}$. Every mode will be analyzed individually. The constants coefficients for each mode are different and they are the major factors that cause the distinct behavior in the daily load curve shape between the modes. A sample mode, hot Fridays, will be discussed and explained in details to clarify the concept of the proposed model and then all other modes are analyzed in the same way.

\subsubsection{Hot Fridays Mode}

Hot Fridays mode means all Fridays from schools period characterized by high temperature values. All hot Fridays from years 2009 and 2010 are displayed as shown in Figure 4.

The similarities between the days of this mode are clear. The daily average day of each day of this mode is calculated. This is done by simply taking the mean of power values at each hour resulting in 24 average power values representing the average mode day. The average mode day for hot Fridays mode is shown in Figure 5a. Then, the mean value of this day is calculated and subtracted from each value resulting in the same curve but with zero mean value. After that, harmonics regression of the form of equation 2 is used to reconstruct the signal. Table 1 shows the values of the constants for the first six harmonics. By evaluating equation 2 at these constants, the modelled mode curve compared with the average mode with zero mean value is shown in Figure 5b.
TABLE 1: CONSTANTS VALUES FOR FIRST SIX HARMONICS

\begin{tabular}{|c|c|c|c|c|c|}
\hline $\mathrm{a} 1$ & $\mathrm{~b} 1$ & $\mathrm{a} 2$ & $\mathrm{~b} 2$ & $\mathrm{a} 3$ & $\mathrm{~b} 3$ \\
\hline 0.398 & -10.89 & 4.259 & -0.281 & -0.536 & -1.632 \\
\hline $\mathrm{a} 4$ & $\mathrm{~b} 4$ & $\mathrm{a} 5$ & $\mathrm{~b} 5$ & $\mathrm{a} 6$ & $\mathrm{~b} 6$ \\
\hline-0.486 & -1.31 & 0.768 & -0.022 & 0.3137 & -0.353 \\
\hline
\end{tabular}
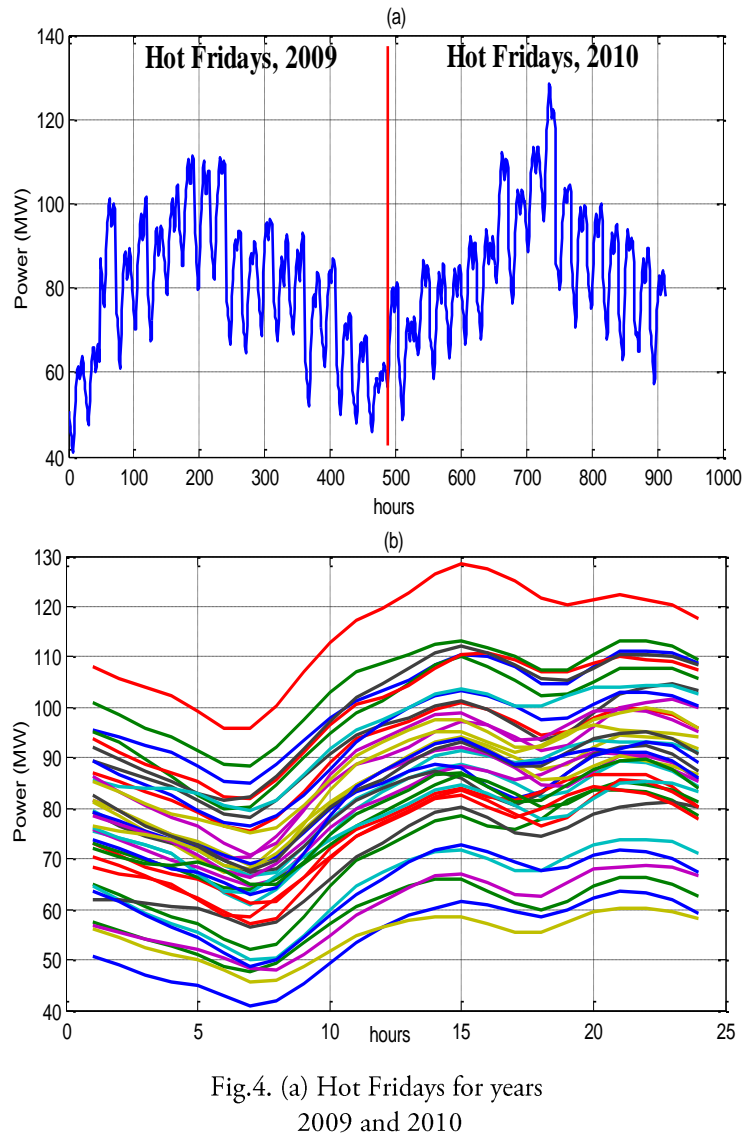

(b) Hot Fridays similarity for years 2009 and 2010

Each average day is modelled by the structure of equation 2 .

Therefore, by specifying the mode number for any "next day" of the forecasted year, 2011, its daily load curve shape and modelled equation are known. So, a clear picture of the shape of each day in 2011 is available now. The next step is to forecast the next day average load consumption for 2011 which will be added algebraically to the mode days to achieve the final desired model. Figure 6 shows the forecasting approach used to forecast a hot Friday, 16/9/2011. 

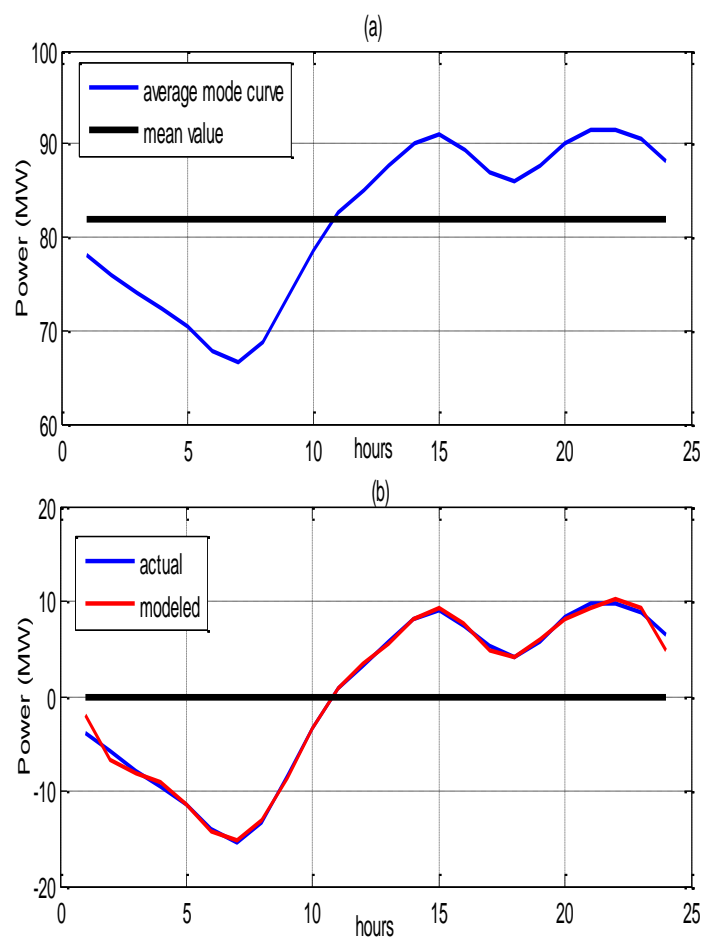

Fig.5. (a) average mode day for 2009 and 2010 (b) actual and modeled average mode day with zero mean value

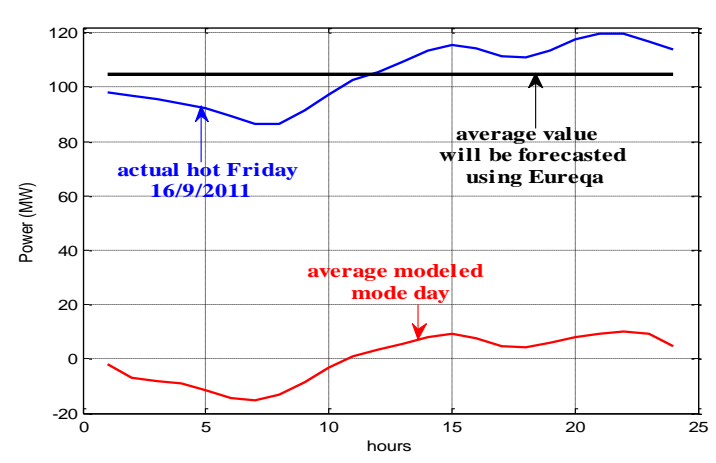

Fig.6. Actual hot Friday from 2011, its non-time varying component, final representative modeled mode day

\subsection{CONSTANT COMPONENT MODEL}

In this analysis, next day average power will be forecasted by regression analysis using Eureqa software. Eureqais a mathematical tool originally created by Cornell's Creative Machines Lab and later commercialized by Nutonian, Inc. The software is used to determine mathematical equations that describe sets of data in their simplest form[26, 27].

After processing the data with the software, the best model with minimum error is:

$$
\begin{aligned}
P_{\text {aveforecassed }}= & 1.048 * T+0.9858 * P_{1}+0.06293 * H-T_{2} \\
& -0.01301 * d n * H_{1} \\
& -0.04053 * P_{3} * \cos \left(5.148-2.754 * d n^{2}\right)
\end{aligned}
$$

Where,

$\mathrm{P}_{\text {avgforecasted }}$ is the predicted average power of the forecasted day. $T$ is the average temperature of the forecasted day. $T_{2}$ is the average temperature two days before. $\mathrm{H}$ is the average humidity of the forecasted day. $\mathrm{H}_{1}$ is the average humidity one day before. $\mathrm{P}_{1}$ and $\mathrm{P}_{3}$ are the average power values before one and three days, respectively. $\mathrm{dn}$ is the date of the forecasted day (i.e. 1,2,....,7). The Eureqa software has given many models that fit the given data. The model with the minimum error has been selected. The model is shown in equation 3. The data included in the modelling are for the years 2009 and 2010 while the data of 2011 will be used to test the effectiveness of the model. Finally, after evaluating the next day average power from equation 3 above, it will be added to the modelled values using equation 2 to reach the final model that will give the power values for all 24 hours for the next day according to the equation:

$$
P_{\text {final }}=P_{\text {model_mode }}+P_{\text {aveforceasted }}
$$

\section{RESULTS AND DISCUSSION}

The load forecast is compared to the actual load data and the error is calculated. The mean absolute percentage error (MAPE) is used to evaluate the performance of the model. It is defined as:

$$
\text { MAPE }=\frac{1}{k} \sum_{i=1}^{k} \frac{\left|P_{\text {act }},-P_{\text {fore }}\right|}{P_{\text {act }}} \times 100
$$

where $P_{a c t_{k}}$ is the actual load, and $P_{\text {fore }_{k}}$ is the forecasted load and $k$ is the number of data points. Typical four intervals selected from different seasons will be shown and forecasted in a next-day-load forecasting basis. Each interval is a one-week period starting from 
Saturday to Friday. The comparison between the forecasted load and the actual load along with MAPE values for the four intervals are shown in Figure 7.

As seen from MAPE values, the performance of the model is satisfactory. In predicting the daily load shape using mode analysis, some days may be transitional mode, i.e. they may be classified to a mode while they actually belong to another mode. This case is present, for example, in the intervals of seasons changing from winter to summer or vice versa. The shape does not change suddenly, but it changes gradually making it difficult whether to classify these days to winter mode or summer mode or even to create a new mode called gradual change between winter and summer. Moreover, within the same mode, some days change shape for unknown reasons such as unpredicted change of weather conditions as sand storm, rainfall or significant change in wind direction or sudden occasion which could not be identified neither from the academic calendar nor from official calendar. As a result of that, the daily load shape changes. After finding the average mode day, it is clear that these abnormal days are different in shape with their mode representative average day. The other factor of errors is the error resulting from forecasting average power for the next day using regression analysis. Because of these two sources of errors, the errors accumulate which affect the final obtained model.

\section{MODEL COMPARISON WITH OTHER PUBLISHED WORK}

In this section, analysis and results of the model used in this work are compared with a published work that studies STLF based on abductive networks. The paper to compare with is reference [28]. Both approaches are applied to the same set of data. The used data

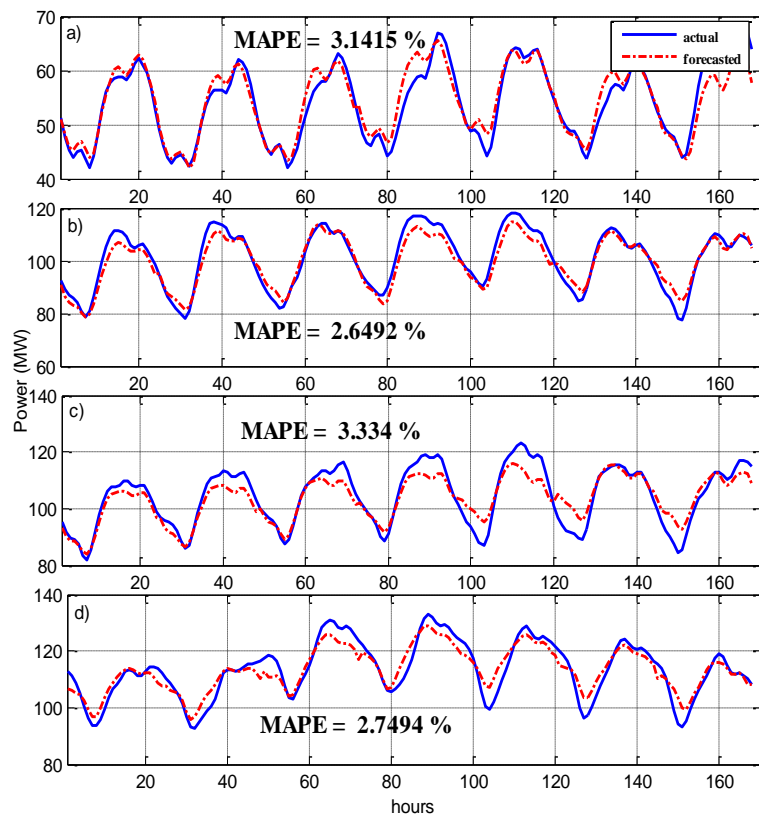

Fig.7. Actual and forecasted load for typical periodsin 2011(a) cold week period (b) hot week period(c) summer vacation season (d)

Ramadan season

source in this analysis consists of measured hourly load consumption in MW and temperature in Fahrenheit for the Puget power utility, Seattle, USA, over the period from 1 January 1985 to 31 December 1990. Years from 1985 to 1989 are used for model building to forecast next day load for the year 1990. Some load characteristics and data nature will be demonstrated. The concept and history of abductive networks in addition to the analysis and data processing approach are shown in details in [28]. The obtained results from abductive networks model in [28] are compared with the results obtained from the model used in this work; both applied to the same set of data.

\subsection{Data Nature AND Modes Classification}

The data consist of measured hourly load and temperature data for the Puget power utility, Seattle, USA, over the period 1 January 1985 to 31 December 1990. The nature of people activities and weather variables in the USA are completely different from those in the KSA. Therefore, different modes categorization will be considered in this type of data. Unlike in 
the KSA, the workdays in the USA are from Mondays through Fridays while the weekend is Saturday and Sunday. Furthermore, holidays such as New Year's Day, Labor Day, Thanksgiving Day and Christmas day are celebrated in the USA but are not observed in the KSA.

Regarding weather conditions, the seasonal change from winter to spring to fall to summer is noted clearly in the USA, whereas in KSA, only summer and winter load curve behavior is present. So, in addition to special days modes, the modes could be classified to winter, spring, fall and summer intervals. With the impact of weather conditions and seasons change, the daily load curve also changes.

As in the KSA, the effect of weekdays and weekend is very significant; each season has weekdays mode (from Mondays to Fridays), Saturday mode and Sunday mode. Figure 8 shows typical weeks starting from Monday to Sunday for each season.

Therefore, as expected, weekdays in every season are different in behavior and higher in consumption than weekends.

For special days analysis, there are also special activities on these days. For example, on Thanksgiving Day, human behavior is completely different from any other normal day. Consequently, every special day will be separated as a mode.

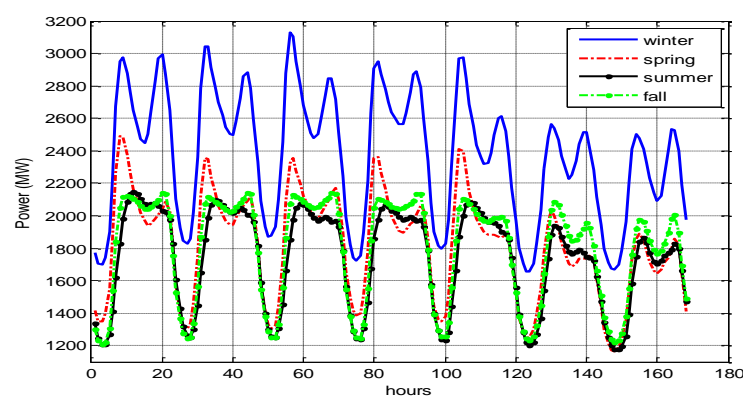

Fig.8. Load profile for a sample week from each season, Seattle, USA, 1989
All special days dates in the USA were found from reference [29]. However, some of them are not official and cannot be identified to be special or not. As a result, there is a problem of how to determine whether these days are special or not. The solution to this is simply by plotting these days, and if any day seems to have special behavior, it will be clear and classified as a separate mode. If not, it will be considered as a normal day and will be classified within its previous days' mode. Figure 9 shows load profiles of some special days in Seattle, USA, 1989. For example, Columbus Day will be considered as a normal day since it does not have special characteristics that are different from the days before or after it. However, Thanksgiving Day has a unique and special behavior which is different from the days before and after it. This supports the decision to separate it as a mode. The same approach is applied to all official and holidays.

In this model analyzing USA data, modes analysis follows the same approach used in the KSA data but with different modes categorizations. However, when forecasting the next day average power value, there is a slight difference when using the Eureqa software. Instead of formulating only one model for all days of the year, 12 models are built representing one model for each month. This is done because of the nature of the data. Unlike in the KSA, USA people's activities in the USA are almost identical in a single Gregorian month for different years. Also, there is no overlapping between holidays, official occasions and social activities for the same period in different years. This means, for example, the behavior of the load shape for the month of August month from years 1985 to 1989 is almost identical. This supports the decision to find a single model for this month as shown in Figure 10. 

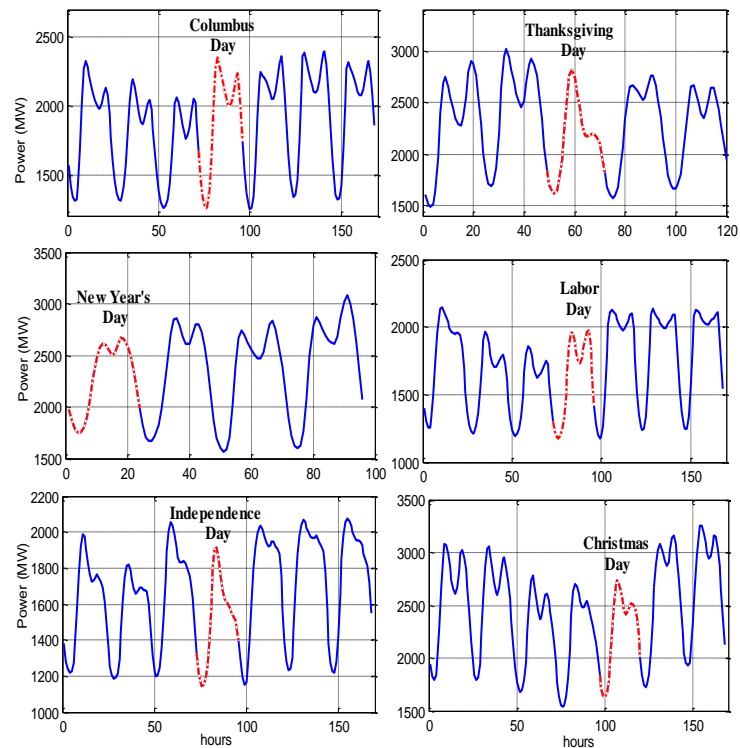

Fig.9. Power profile for some special days in Seattle, USA, 1989

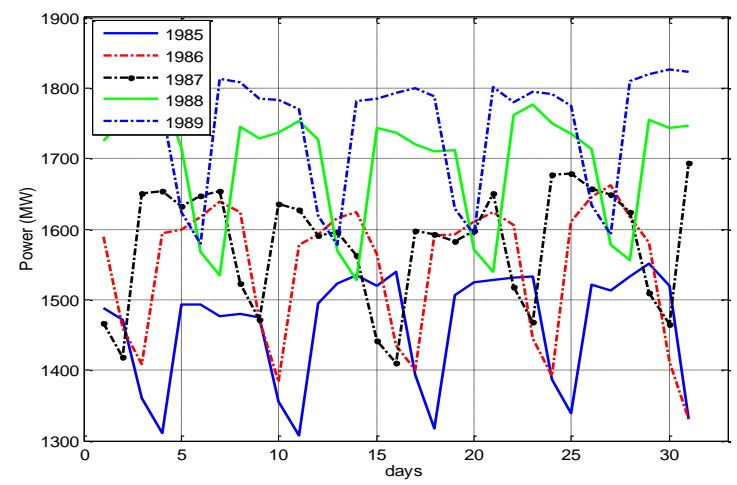

Fig.10. Similarity of the shape of the average power for the days of August for years 1985-1989

Using Eureqa, the equations for all months to forecast the next day average power are shown in the appendix. Full-day load curves were forecasted using abductive networks models for some selected days of the evaluation year. The results of these forecasted days using abductive networks are shown in Figures 11a, $12 \mathrm{a}$ and the results using the mode-regression based model for the same days are shown in Figures 11b, 12b. Also, Table 2 shows the MAPE comparison between the two models for some other selected days.

For abductive networks model, it is clear that the forecasting accuracy is the best for the workday and poorest for the holiday due to the fewer examples of holiday load patterns encountered during training. The best MAPE for the holiday day (Labor Day) is achieved by using the mode-regression based model. This is due to the fact that this day is considered alone as a mode and the model keeps its shape during all the model building years that are very similar in behavior. During holidays, load behavior is not affected by temperature considerably. The main affecting factor is people activities.
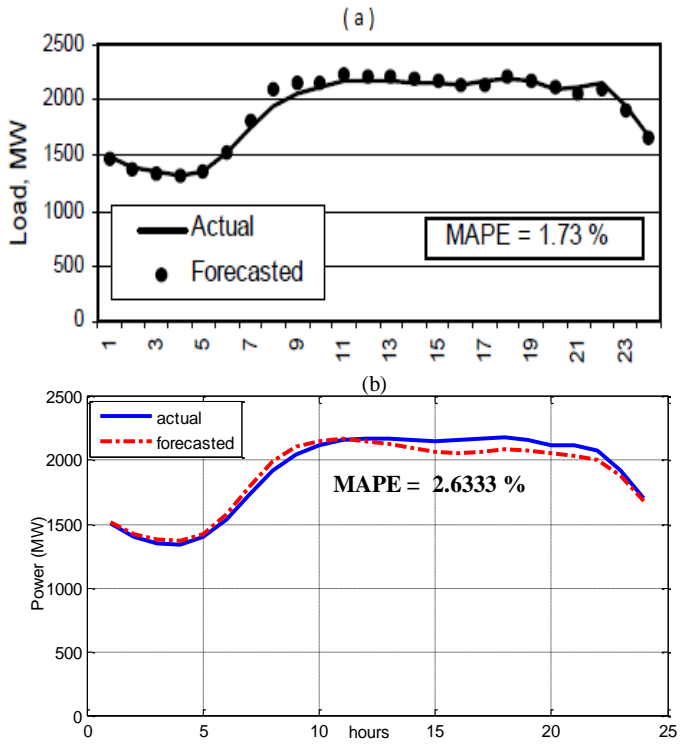

Fig.11. Actual and forecasted load profile for Wednesday 8 Aug, 1990 (working day) using:(a) abductive networks (b) mode-regression based model

(a)
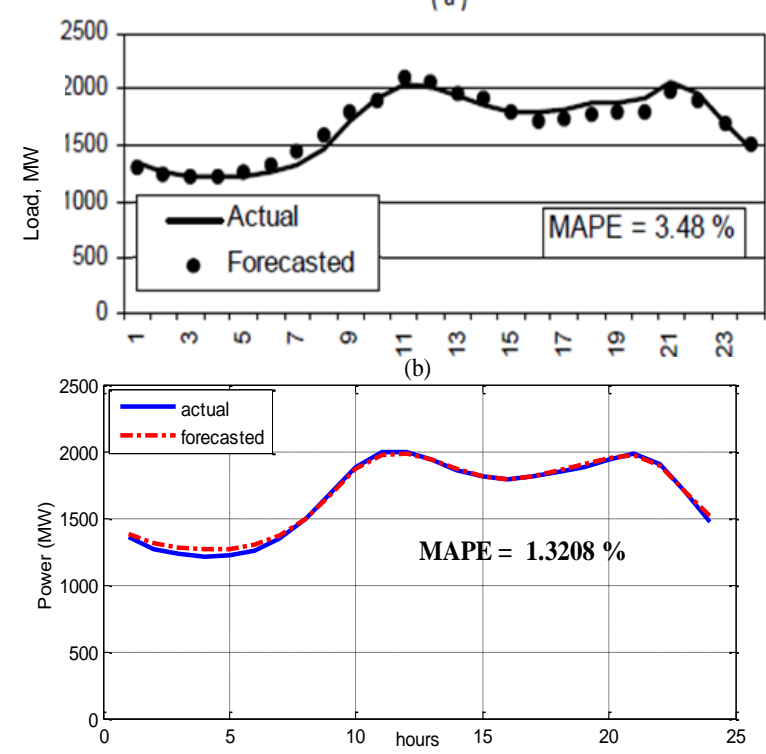

Fig.12. Actual and forecasted load profilefor Monday 3 Sep, 1990 (Labor Day)using: (a) abductive networks,(b) mode-regression based model 
TABLE 2: MAPE COMPARISON BETWEEN THE TWO MODELS FOR SOME SELECTED DAYS

\begin{tabular}{|c|c|c|c|c|}
\cline { 2 - 5 } \multicolumn{1}{c|}{} & \multicolumn{4}{c|}{ MAPE, \% } \\
\cline { 2 - 5 } \multicolumn{1}{c|}{} & 8-Aug & 11-Aug & 12-Aug & 3-Sep \\
\hline $\begin{array}{c}\text { Mode- } \\
\text { regression }\end{array}$ & 2.63 & 2.89 & 2.32 & 1.32 \\
\hline $\begin{array}{c}\text { Abductive } \\
\text { networks }\end{array}$ & 1.73 & 2.3 & 1.97 & 3.48 \\
\hline
\end{tabular}

\section{CONCLUSION}

This paper presents the results of the formulated mode-regression based model for residential STLF. In this model, days that have similar characteristics are identified and classified into groups called modes. Then, the representative average day for the mode is found and the relevant model is constructed using harmonics regression. After that, regression analysis using Eureqa software is used to forecast the next day average power. Finally, the two components are combined to reach the final next day load-forecasting model.

The results obtained from this work are satisfactory when dealing with frequent modes in the year. In addition, very satisfactory results are achieved when dealing with modes that are not frequent; or have few days like Eid mode and Ramadan mode.

Moreover, the performance is very satisfactory for modes that depend mainly on people activities. However, once the mode is affected by some random environmental factors, the performance is less satisfactory. This is attributed to the nature of formulating the model.

As an extension of this work, further development models may include more weather parameters data such as wind speed and direction, rainfall and sky condition which have an impact on the load. In addition, this work is only to forecast the next day load.
Hence, the next week load forecasting could be a continuation for this work. Additionally, load type could be extended to include aggregated load, commercial and industrial loads. The model could be used also for medium and long term forecasting but here the average daily load forecasting has to be extended to include medium period and larger.

\section{APPENDIX}

Next day Average load models for each month, USA data:

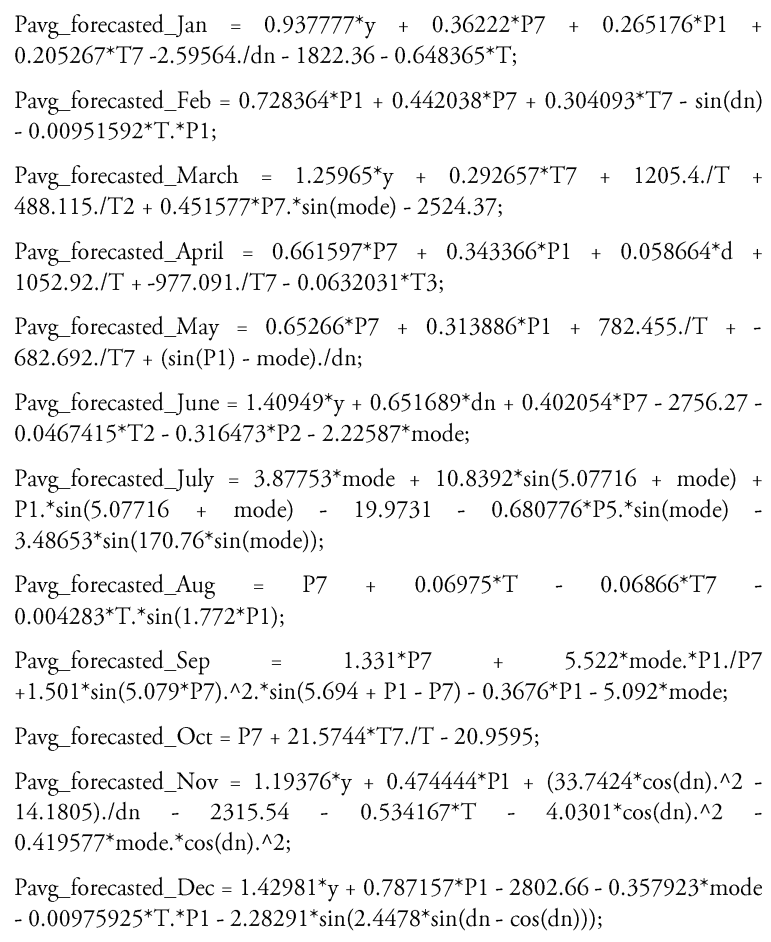

Pavg_forecasted_Dec $=1.42981^{*} \mathrm{y}+0.787157^{*} \mathrm{P} 1-2802.66-0.357923^{*}$ mode $-0.00975925^{*}$ T. $*$ P $1-2.28291 * \sin \left(2.4478^{*} \sin (\mathrm{dn}-\cos (\mathrm{dn}))\right)$;

\section{REFERENCES}

[1] Fahad Al-Turki, "A Fuzzy Neural Approach For Forecasting Peak Power Demands", Journal of King Saud University, 14(1), 29-40, 2002.

[2] Zengyanfei W u yinbo, "Design of Short Term Load Forecasting model based on BP Neural network and Fuzzy Rule", International Conference on Electric Information and Control Engineering (ICEICE), 5828-5830, 2011.

[3] ArashGhanbari, EsmaeilHadavandi and Salman Abbasian-Naghneh, "Comparison of Artificial Intelligence based Techniques for Short Term Load Forecasting", Third International 
Conference on Business Intelligence and Financial Engineering, 6-10, 2010.

[4] S .ChenthurPandian, K. Duraiswamy, C. ChristoberAsirRajan, N. Karangaraj, "Fuzzy approach for short term load forecasting", Electric Power System Research, 76 (6,7), 541548, 2006.

[5] Kun-Long Ho, Yuan-Yih Hsu, Chih-Chien Liang and Tau-Shin Lai, "Short Term Load Forecasting of Taiwan Power System Using A KnowledgeBased Expert System", IEEE Transactions on Power Systems, 5(4), 1214-1221, 1990.

[6] S. Rahman, O. Hazim, "Load forecasting for multiple sites: development of an expert systembased technique", Electric Power Systems Research, 39(3), 161-169, 1996.

[7] K. H. Kim, J. K. Park, K. J. Hwang, and S. H. Kim, "Implementation of hybrid short-term load forecasting system using artificial neural networks and fuzzy expert systems", IEEE Transactions on Power Systems, 10(3), 1534-1539, 1995.

[8] Azzam-ul-Asar, Syed RiazulHassnain, and Affan Khan, "Short Term Load Forecasting Using Particle Swarm Optimization Based ANN Approach”, Proceedings of International Joint Conference on Neural Networks, 1476-1481, 2007.

[9] Chao-Ming Huang, Chi-Jen Huang, and MingLi Wang, "A Particle Swarm Optimization to Identifying the ARMAX Model for Short-Term Load Forecasting”, IEEE Transactions on Power Systems, 20(2), 1126-1133, 2005.

[10] Wang Xuan, Lvjiake, Wei Chaofu and XieDeti, "A Hybrid Particle Swarm Optimization Neural Network Approach for Short Term Load Forecasting", 4th International Conference on Wireless Communications, Networking and Mobile Computing, 1-5, 2008.

[11] S.J. Yao, Y.H. Song, L.Z. Zhang, X.Y. Cheng, "Wavelet transform and neural networks for short-term electrical load forecasting”, Energy Conversion \& Management, 41(15), 1975-1988, 2000.

[12] Tai Nengling, J“urgenStenzel, Wu Hongxiao, "Techniques of applying wavelet transform into combined model for short-term load forecasting", Electric Power Systems Research 78(3), 525-533, 2006.

[13] Zidan Bashir and El-Hawary, M.E., "Short Term Load Forecasting by using Wavelet Neural networks”, Canadian Conference on Electrical and Computer Engineering, 163-166, 2000.

[14] Slobodan Ružic',AcaVuckovic', and Nikola Nikolic', "Weather Sensitive Method for Short Term Load Forecasting in Electric Power Utility of Serbia”, IEEE Transactions On Power Systems, 18(4), 1581-1586, 2003.

[15] A.M. Al-Kandari, S.A. Soliman, M.E. El-Hawary, "Fuzzy short-term electric load forecasting", Electrical Power and Energy Systems, 26(2), 111122, 2004

[16] Amral, N. Ozveren, C.S., King, D., "Short Term Load Forecasting using Multiple Linear Regression”. 42nd International Universities Power Engineering Conference, 1192-1198, 2007.

[17] Eugene A. Feinberg, Dora Genethliou, “Applied Mathematics for Restructured Electric Power Systems", Springer US, 2005.

[18] ParasMandal, TomonobuSenjyu, Naomitsu Urasaki and Toshihisa Funabashi, "A neural network based several-hour-ahead electric load forecasting using similar days approach”, International Journal of Electrical Power and Energy Systems, 28(6), 367-373, 2006.

[19] Yu-Jun He, You-Chan Zhu, Jian-Cheng Gu and Cheng-Qun Yin, "Similar Day Selecting Based Neural Network Model and Its Application in Short-Term Load Forecasting", Proceedings of the Fourth International Conference on Machine Learning and Cybernetics, Guangzhou, 47604763, 2005.

[20] Espinoza, M.,Joye, C., Belmans, R. and De Moor, B., "Short-Term Load Forecasting, Profile Identification, and Customer Segmentation: A Methodology Based on Periodic Time Series", IEEE Transactions on Power Systems, 20(3), 1622-1630, 2005.

[21] Amjady, N., "Short-term hourly load forecasting using time-series modeling with peak load estimation capability", IEEE Transactions on Power Systems, 16(4), 798-805, 2002.

[22] Himanshu A. Amarawickramaa, Lester C. Hunt, "Electricity demand for Sri Lanka: A time series analysis", Energy 33(5), 724-739, 2008.

[23] Chen, Bo-Juen, Chang, Ming-Wei and Chih-Jen lin, "Load forecasting using support vector Machines: a study on EUNITE competition 2001", IEEE Transactions on Power Systems, 19(4), 1821-1830, 2004. 
[24] Amit Jain and Satish.B, "Integrated approach for short term load forecasting using SVM and ANN, TENCON 2008", IEEE Region 10 Conference, 1-6, 2008.

[25] M. Mohandes, "Support Vector Machines for Short-Term Electrical Load Forecasting", International Journal of Energy Research, 26(4), 335-345, 2002.

[26] Schmidt M., Lipson H., "Distilling Free-Form Natural Laws from Experimental Data, 324(5923), 81-85, 2009.
[27] Schmidt M., Lipson H., "Eureqa (Version 0.98 beta) [Software]", Available from www.nutonian.com, 2013.

[28] Radwan E. Abdel-Aal, "Short-Term Hourly Load Forecasting Using Abductive Networks", IEEE Transactions on Power Systems, 19(1), 164-173, 2004.

[29] http://www.timeanddate.com/calendar/?year=198 8\&country 
التببؤ قصير المدى للأحمال الكهربائيه باستخدام معادلات الانحدار و مجموعات الأيام

$$
\begin{aligned}
& \text { أحمد الصبحي1، شكري بالحاج أحمد2 } \\
& 1 \text { قسم تقنية القوى الكهربائيه بكلية ينبع الصناعية }
\end{aligned}
$$

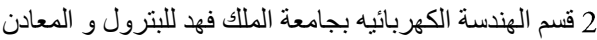

الملخص:

يعرض هذا البحث نموذج تحليلي للتنبؤ قصير الددى للأحمال الكهربائيه باستخدام معادلات الانحدار و مجمو عات الأيام لمنطقة سكنيه بمدينة ينبع الصناعيه بالمملكه العربيه السعوديه. تم جمع بيانات تشمل الاستهلاك الكهربائي و درجة الحر ارهو الرطوبه لكل ساعه على مدى ثلاث سنو ات من 2009 إلى 2011. تعتمد الفكره الأساسيه لهذا البحث على توزيع كل الأيام المتشابهه في الخو اص إلى مجموعات و ذلك اعتمادا على الظروف البيئيه و النشاطات الخاصه بالسكان و ذلك بتقسيم المنحنى اليومي إلى جزأين: الجزء الأول هو التتبؤ فقط بشكل المنحنى مع عدم أخذ القيمة المتوسطه للمنحنى بالاعتبار و افتر اض مساو اة هذه القيمة المتوسطه بالصفر. تم التتبؤ بهذا الجزء باستخدام معادلات الانحدار الخاصة بالدوال الدائريه ( جا - جتا ). الجزء الثاني هو التتبؤ بالقيهة المتوسطه للاستهلاك الكهربائي لليوم القادم. تم التنبؤ بهذا الجزء باستخدام البرنامج ( إيروكا ). في النهاية، تم جمع المعادلتين لكل جزء جمعا جبريا و التي تنشئ النموذج النهائي للتنبؤ بقيم الاستهلاك الكهربائي للأربع و عشرين ساعه القادمه. أظهرت الاختبارات التي أجريت على هذا النموذج التحليلي نتائج مرضيه. لإظهار فعالية النموذج المقترح , أجريت مقارنة على بيانات مختلفة باستخدام طريقة أخرى في أحد الأبحاث المنشوره ثم استخدم النموذج المقترح على هذه البيانات و تم التوصل لنتائج مرضيه و مقاربه للنتائج المتوصل إليها في البحث المنشور. 